the head was complained of, but there was "an absence of the various kinds of involuntary movements (such as cramps, twitchings, jerking, trembling) which are prominent symptoms of inflammation of the cerebrum." * Nor was there any of that irrregularity in the rapidity and strength of the pulse which Dr. Brown Séquard also appropriately describes as the frequent characteristic of cerebral inflammatory softening. 'The genitals were unaffected. The respiration was not interfered with. There was no serous discharge from the ear ; but deafness on the affected side, lowering of the voice with some diffi. culty in articulation, and also amaurosis, were well-marker symptoms. There was neither facial palsy nor squinting-no paraplegia, dysphagia, or anæsthesia of any part; and, lastly, though convulsions preceded death, there was an entire absence of coma and of its characteristic phenomena-impeded circula. tion and respiration, paralysis of the velum palati, and conse. quent blowing-out of the cheeks; and there was no relaxation of the sphincters.

The post-mortem examination displayed several points of interest. In the first place, the evidences of injury externally were but small, and afforded no adequate indication of the amount of mischief inflicted on the parts within the skull. The aperture of entrance of the bullet was rounded and regular, with an inverted margin, and barely admitted the tip of the little finger; but the work of destruction effected by the charge clearly commenced directly after it had entered the petrous portion of the temporal bone. And vast was the havoc there made : the temporal bone was splintered and broken up into so many fragments that the contour of the petrous portion, when looked at from above the calvaria having been removed), conld not be made out at all. In marked contrast to this extensive destruction of bone, was the localized nature of the injury to the cerebellum; the anterior part of the left lobe, which had received the shock of the apex of the petrous bone, alone affording evidence of the effects of the injury. The un injured condition of the tentorium and falx cerebelli is a good proof of the strength and power of resistance existing in the dura mater, and further helps to account in some measure for the confinement of the lesion to one lobe of the cerebellum. The presence of a clot in the posterior lobe of the cerebrum at a point above the tentorium corresponding to the injured portion of the cerebellum lying immediately below that membrane, is another interesting circumstance. Doubtless the tentorium was able, in consequence of its elastic nature combined with its strength, to resist the impetus of the explosion, while the weak coats of the cerebral vessels were torn by the violence of the concussion, and hence the extravasation found in the posterior lobe. The last but not the least important feature of this pathological examination was presented in the condition of the carotid artery. The bony canal through which that vessel enters the skull was literally comminuted, and yet the artery escaped rupture; moreover, although the bullet. in its trajet, had even bl ckened and contused its walls, yet no destruction of them occurred at any part, and there was an entire absence of extravasation of blood both within and without the skull The faculty possessed and so often manifested by arteries, of withstanding injuries which simultaneously smash bones and lacerate muscles, was well exemulified in this case.

Case of fracture of the nasal bone, proving fatal by homor rhage. Charles $\mathrm{C}-$, shoemaker, aged sixty, was drinking at a public-house about half past ten P.M. on August 6 th, 1855 , when he received a blow on the nose from the waiter, who in tended to have struck another man. Half a pint of blood was lost at the time, and then by the use of cold water the bleeding stopped, and he went home. At dinner time on the 8 th inst., bleeding recurred to the extent of "two quarts;" cold again stopped it, and he went on well till the 10th, when another and violent hrmorrhage came on, which continued all night, and at eight A.M. on the llth he was brought to the Queen's Hospital in a weak and anæmic state. Wine and ammonia were given him, and the anterior nares on the right side plugged with lint steeped in tincture of sesquichloride of iron. This stopped the bleeding until three A. M. the following morning, when it was necessary to plug both anterior nares with lint steeped in tincture of iron. No further bleeding took place till the 14th instant, when it came through the mouth with great rapidity. The posterior nares were then plugged on the right side, as well as the anterior. No more hromorrhage took place that day; but on the following day a little occurred from the left nostril, but the application of ice soon arrested it, and no further loss of blood took place. He hecame. however, weaker

* I quote Dr. Broivn-néquard's wris, uset in speaking of cases of cerebellar disease, in his admirable lectures in THE $I_{\Delta N C B T}$, as exactly applicable to this case. every day, in spite of exgs, wine, and other stimulants. The plugs were removed with care, and after considerable difficulty, on the 25th inst. No improvement in his general condition took place, and he gradually sank, dying at three A.M. on A ugust $28 \mathrm{th}$.

The post mortem examination discovered the body in a greatly emaciated and avæmic state. All the viscera were blanched, but healthy. 'The fore part of the right nasal bone was fractured obliquely, so as to separate, but without marked tendency to depression, a piece of bone a quarter of an inch square. The mucous membrane was absent from the septum nisi and turbinated bones. There was no injury either to the skull or brain.

This case is remarkable from the fact of the persistence of the bæmo:rhage. Styptics and plugging the nares were resorted to, but both were equally unavailing, and the man no doubt died exhansted from the repeated losses of blood. I do not, upon reviewing the history of the case, think that anything more could have been done for him; but had the posterior nares been plugged at the time of the injury the result might, verhaps, have been different.

Newhall-street, Birmingham, Jume, 1862.

ON

\section{EMPYEMA FROM ABSCESS OF LUNG; THORACENTESIS.}

\section{BY LEONARD W. SEDGWICK, M.D.}

R. S-- a aged fifty.eight, a medical man, had an attack of typhus fever in the spring of 1850 . He was spare, not very strong, subject to indigestion, and had latterly been much harassed by his attendance on cases of fever. After three or four weeks' illness a bad cough came on, with scanty, difficult expectoration of slimy, reddish secretion, full of small airbubbles; the cough was paroxysmal and suffocative. The lower and middle lobes of the right lung were quite consolidated; bronchial breathing was most notable. This state of things continued with more or less intensity for some ten days, when rigors, evening hectic, night-sweats, and great depression en. sued. Coincidently there was to be heard about the centre of the hepatized lung a moist rhonchus, which gradually increased in extent and intensity, and at the same time the expectoration became more purulent, and by-and-by offensive and somewhat sanious. The pulse became very weak and feeble; no appetite. The stethoscopic signs became more notable; indications of 2 cavity presented themselves, and the breathing became amphoric whenever the expectoration had been so free as partly to empty the cavity. Then a bulging was perceptible between the sixth and seventh ribs, about their middle, and at the same time signs of fluid confined to the lower third of the chest were manifest; the upper line of fluid was not movable, and it rose much higher posteriorly than anteriorly. The cough was now most troublesome and spasmodic, and the expectoration positively filthy. I introduced a trocar, and removed more than a quart of the most stinking pus $I$ ever smelt. When the fluid had ceased running, air in great abundance passed through the canula, and when the patient conghed the current was so strong that a candle, which happened to be near, was blowu out. The next day all the symptoms were much relieved; steadily and gradually health was restored, and by September the patient was out of loors. Soon after this the opening, which had re mained patent for between two or three months, closed, the cough left, and there were no siuns of disorder save the falling in of that side, the approximation of the ribs, the duluess on percussion, and the presence of harsh tubular breathing for a considerable distance around the site of the opening. During the winter he resumed his professional duties, and was able to attend occasionally to night calls. In the early spring of 1851 he got cold; nothing of moment-- a simple catarrb. hut it left with him a cough, which, at first trivial, became by degrees more troublesome. He spat up with it at first mere bronchial mucus; after a while slight occasional streaks of blood would appear, and at intervals he could taste something of the old turnipy flavour. Soon general symptoms set in; he had slight rigors; became thinner; lost his inclination for food; perspired 
at night, and he coughed up more and nastier stuff, mu'o purulent matter, and more of the latter than the former. The loc.l signs were increased - dulness, large mucons rhonchus, and som what diminished vocal fremitus; these intensifiel as the general symptoms developed themselves. He took to bis bed, and rapidly grew worse. When this state of things had con. tinued for two or three weeks, an attack of angioleucitis made its appearance in the right, leg, with very much œ lema. In three days it subsided to a great extent, and the lymphatics of the left leg were subjected to the same diseased action. The patient now seemed rapidly sinking, and it behoved one, if possible, to do something for his relief. The solitlification of the lung was clearly due mainly to thid, and that fluid, pus; but from the previously injured condition of the organ it was impossible distinctly to pronounce where the solidity was from hepatization of the lung and where from pus. Under these circum. stances, I pushed a very fine exploring trocar into the chest between the sixth and seventh ribs, and fortunately hit upou the pus, fetid and stinking as of old. I immediately withdrew the instrument, and introdnced a larger one, and by means of it withdrew at least three pints of abominably putrid pas; air in abundance followed. Immediately a great change for the better was perceptible in the patient, and without any interruption he got well. The purulent discharge from the side became less and less; but warned by the result of the previons attack, I took measures to prevent the closing up of the track. A plug or nail of gutta percha, about an inch and a half long, the thickness of a small goose-quill, and with a flat head, was constantly worn, and secured in its position by a piece of sticking-plaster. This he remover every night and morning, and by straining he emptied the cavity, and so prevented any accumulation of pus. When the sac was emptied air condd always be expelled from the opening. In the conrse of time the pus became thinner and smaller in quantity. Sometimes he did not remove it oftener than every two or three days, and frequently only about half a drachm of thin semi-purulent fluid would escape. He got up his strength and looks, and could go about without any incouvenience at an ordinary pace, but was short of breath when hurried. Fe resumed his duties as a country surgeon, attended an occasional midwifery case, and considered himself in fair health. He got over the ensuing winters very well, until October, 1856, when he began to fail in strength. He gradually lost his appetite, got thinner, had some what more cough, and much more discharye from the side. Slowly he got weaker and worse; the cavity, which seemed to have become a mere fistulous passage, giving no physical indication of its existence save a dull percussion note for an inch or two around the opening, got larger and larger, and in A pril, 1857 , he died, at the age of sixty-five. There was no postmortem examination.

Unusual as it is for empyema to depend upon the opening of a simple non-tubercular abscess in to the pleural cavity, $I$ do not thiuk that any donbt can exist as to its occurrence in this case. The physical signs of pneumonia preceded bv some time any indications of fluid, and were very notable. In the weak and enfeebled condition of the patient, it can easily be imagined that the infiltration of lung-tissue, possibly of typhous inaterial, would easily pass into pus, and that a degeneration or ulceration of the lung, as shown by the fetid expectorition, should ensue. But the opening into the bronchial tube was not, sufficiently large for the free exit of the pus, and at every cough the contents of the abscess would be forced nearer and nearer to the pleural surface, and at last throngh it. Perhaps before this had happened, some adhesion of the two pleural surfaces had taken place; certainly the pleural effusion was confined to the lower part of the chest. When it was evacuated the ribs fell in, and the cavity contracted and cicatrized; of course it would still retain its connexion with the bronchial tube. The next time he had catarb, some of the bronchial secretion would remain in this blind tube, and could not be expectorated. Lying here exposerl to the air, it would undergo putrefaction; would cause the offensive taste again; would, as is probable from the streaks of blood, induce ulceration, and so, by an eazy transition, all the formidable events of the previous attack. After evacuating it the second time, I deter mined on preserving patent the fistulous openin result was most satisfactory; comparatively yood health was preserved for some years, and the patient in the end seemed to die of general decay of vital power rather than any local in. crease of disease.

Phthisis; pneumothorax; thoracentesis. - J. J-, aged twentr-four, an intemperate liver, had been phthisical for more than a year. He had a large cavity in the upjer lobe of the left lung. There was much tubercular consolidation and small cavities in the right lung. Early in November, 1858, whilst in the last stage of phrhisis, and apparently rapidly siuking, acute pain suddenly came on in the left chest. I found him almost collapsed, nearly pulseless, and racked with agonizing pain. There was a loud friction sound in the lower half of the left side; in the upper part the percussion note was tympanitic; there was lund amphoric breathing and most distinct inetallic tinkling. To my great surprise, he rallied from the severity of the symptoms, but every day he had rigors, and still some pain in the sirle; fuid began to accumulate in the pleura; the bre ithing became most difficult; the heart was pushed over to the right sile; the upper part of the chest was tympanitic, but the space i'as diminishing daily; in short, the patient was siuking from suffocation.

In the hope of afforiling temporary relief, and making his death less painful, I performed thoracentesis, and removed a very large quintity of fetid pus ; air in abundance followed the next diy. For three weeks he steadily improved; the breathing was natural, the pulse slower, and is really seemed as if the patient woull get well. Unfortunately, at this time much influenza was astir. His wife, amongst others, was attacked, and he followed immediately with similar symptoms-coryza, snefzing, increased cough, -and in a week he died. I can hardly dare to bope that, if this unfortunate complication had not supervened, my patient would have got well; but there was very much improvement after the operation, and much prospect of its continuance; anyhow, the case is interesting. Similar ones may occur again, and under more favourable circumstances it may be hoped that the very notable temporary improvemeut which occurred in my case might beenme per$\mathrm{m}$ nent. At least, $\mathrm{I}$ had the satisfaction of relieving him from immense distress and pain-a not unworthy object. Is it fanciful to suggest that a time may come when we may successfully treat advanced cases of phthisis by establishing an external opening for the evacuation of the products?

Baker-street, Portman-square, June, 1862.

\section{MADEIRA AND ITS CLIMATES; WITH}

METEOROLOGICAL OBSERVATIONS, 1861-62.

\section{BY G. H. BRANDT, M.D., Paris.}

AxthovgII so much has been written and said about the island of Madeira and its climate by professional men of all countries, and by the thousands who have visited it for the benefit of their health, still, in our opinion, there are few who have appreciated to their full extent all its qualities, and fewer still who have availed themselves of all its advantages.

The mest important feature of Madeira is that it possesses every kind of climate that invalids suffering from pulmonary diseases can require; this is chiefly owing to its peculiar geographical situation and formation. The fact of the greater portion of invalids residing in the centre of the town, where the climate is always the same, reminds us of those who believe in a panacea which is to cure all diseases. Can one single therapeutic agent, (however good it may be) affect in the same way individuals from different countries, with different constitutions, temperaments, and idiosyncrasies? It is absurd to suppose so, and yet it is what is constantly done year after year by those who resort to Maderia.

The majestic amphitheatre of Funchal is naturally divided into three districts-east, central, and west; the south being formed iy the bay, and the north $1 \nabla$ hills of different heights, varying between one hundred and thousand feet, beyond which are mountains of much greater altitude. The east is the most sheltered part of Funchal, being protected from the north and north-east winds by the surronuding mountains. The centre, owing to numerous water courses constantly running in every direction, and sometimes overflowing, constitutes the dampest district. The west is dry and warm. To convince us still more of the varieties of climate within a small range, we have only to glance at the particular vegetation in each of these districts, and we shall find that those vegetables which require a wet soil aud damp atmosphere (such as the banana, inhame, loquat, \&c.) thrive more luxuriantly in the central district. The western district produces the finest wine, owing to its particularly dry soil, and the perfect maturity at which the grape 